\title{
A Licence to Sell
}

\section{Dear Reader,}

Although their participation in the 1800s was short, diesel and gas engines are in their third century of existence and it is interesting to note how ways of selling and developing large engines have both changed and remained the same.

As Hans-Jürgen Reuß points out in the book he wrote to celebrate the centenary of the Diesel patent, Hundert Jahre Dieselmotor: Ideen, Patente, Lizenzen, Verbreitung, the licensing business model was the way ideas were marketed at the end of the $19^{\text {th }}$ Century and Rudolf Diesel essentially followed the example set by James Watt with his steam engines.

This is not surprising when we read elsewhere what was involved in getting the first steam locomotive to reach Germany, the Adler, from Robert Stephenson's works in Newcastle, England to the Nuremburg-Fürth area. It is similar logistical obstacles to transport that have perpetuated the licensing model for large low speed engines. And although transport of smaller two-strokes is still feasible, the excellence of the latest production facilities and their proximity to shipyards render them unbeatable centres of two-stroke engine production.

Topically, we have seen apparent changes in the two-stroke business model in the past three years, but essentially the established customs and practices of licensing to third party engine builders looks set to endure.

Not so on the medium and high speed engine sides. Apart from the greater suitability of four-stroke engines to transport to their place of installation, a number of papers at both the 2013 and 2016 CIMAC World Congresses reported on engines brought to readiness for serial production via collaborations between European consulting engineers and clients in another hemisphere.

Aside from the fact that such partnerships are for the duration of the development process only, this type of arrangement has an essential similarity with licensing. A fee is paid that allows an engine builder access to know-how from a partner who is in a position to maintain an up-to-date fund of knowledge on state-of-the-art diesel and gas engine technology. Underlining this final point are the stated ambitions of the engine builders using consultants to sell their new diesel and gas engines on global, not just local markets.

Like the licensing business model, the engine builder/consultant partnership is proving itself an excellent way of establishing broad parity in engine technology in all regions of the globe. This is to be welcomed because no region of the globe is unaffected by engine emissions.

$$
\text { Gonathan Wallas }
$$

\section{Jonathan Walker}

Chief Correspondent, MTZindustrial

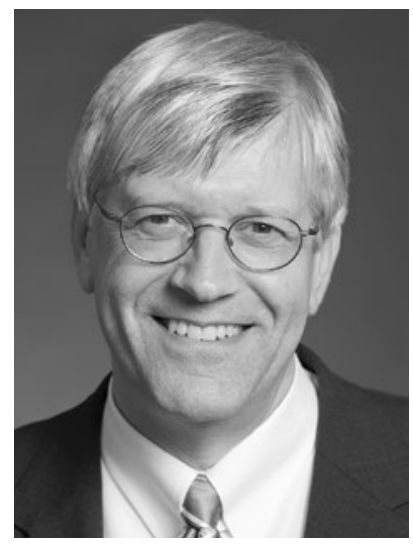

WTZ RoBlau

$10^{\text {th }}$ Dessau Gas Engine Conference April 06-07 2017 in Dessau-Roßlau, Germany

On April 6-7 2017 the WTZ Roßlau will hold the 10th Dessau Gas Engine Conference. The conference will take place in the conference room of the Golfpark Dessau.

The participants will get the chance to learn something about technological developments and can discuss the possible further development of gas engines.

Well-known companies and institutions from the engine industry, research and education will actively shape the lecture program in the sessions

1. Gas Engines - new and further Development

Chairman: Professor Andreas Wimmer LEC/Technische Universität Graz

2. Dual Fuel Combustion Chairman: Professor Helmut Tschöke Otto-von-Guericke-Universität Magdeburg

3. Simulation, Development Chairman: Professor Lars M. Nerheim Bergen University

4. Concept and Strategies Chairman: Professor Georg Wachtmeister Technische Universität München

5. Fuel Gas, Emissions Chairman: Professor Horst Harndorf Universität Rostock.

At the exhibition accompanying the conference you will have the opportunity to present your company, products and services.

The complete conference program and registration procedures are available online at www.wtz.de.

For more information please contact the following address:

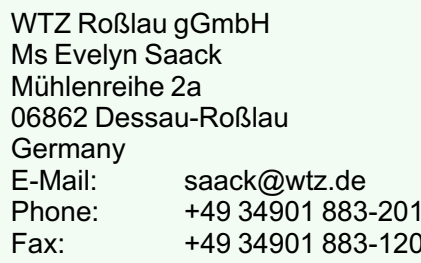

Program and Registration: www.wtz.de 